\title{
Influence of Silymarin on Valproic Acid Induced Hepatotoxicity in Adult Male Albino Rats
}

\author{
Shereen A. El-Khateeb, Manar H. Arafa ${ }^{1}$, and Taiseer R. Ibraheem²
}

${ }^{1}$ Department of Forensic Medicine and Clinical Toxicology
${ }^{2}$ Department of Pathology

Faculty of Medicine, Zagazig University, Zagazig, Egypt.

\begin{abstract}
Introduction: Valproic acid (VPA) is a widely prescribed antiepileptic drug, which might induce serious hepatic disorders. Silymarin is currently used as a supportive therapy of liver disorders. Aim of the study: In this study we evaluated the protective effects of silymarin on valproic acid induced hepatotoxicity. Material and Methods: seventy adult male albino rats were divided into 7 groups (10 each), (Ia) negative control, (Ib) positive control, (II) silymarin group, received $17.5 \mathrm{mg} / \mathrm{kg}$. (IIIa) low dose VAP group, received $200 \mathrm{mg} / \mathrm{kg}$, (IIIb) high dose VAP group received $400 \mathrm{mg} / \mathrm{kg}$ (IVa) low dose $\mathrm{VPA}+$ silymarin group and (IVb) high dose VPA + silymarin group received doses as previously mentioned. The drugs were gavaged once daily, 6 days/week for 8 weeks, at the end of the experiment rats were sacrificed and estimation of alanine aminotransferase (ALT) and alkaline phosphatase (ALP) in the blood, malondialdehyde (MDA) and glutathione peroxidase (GSH-Px) in liver tissues and histopathological and immunnohistochemical examination of liver tissues were carried out. Results: this study showed significant increase in serum ALT, ALP and hepatic MDA contents while GSH-Px activity significantly reduced (especially in high dose VPA group) when compared with the control. Histopathological changes showed patchy microvesicular steatosis, focal necrosis of hepatocytes, dilated congested central vein and sinusoids. Immunolocalization of Bcl-2 revealed dose dependent weak cytoplasmic staining in the hepatocytes surrounding the central vein. VPA+ Silymarin groups showed partial improvement. Conclusion: It concluded that VPA has dose dependent toxic effects on liver that might be ameliorated by concomitant use of silymarin.
\end{abstract}

Keywords valproate, silymarin, oxidative stress, ALT, ALP, MDA, GSH-Px, Bcl-2

\section{Introduction}

Valproic acid (2-propyl-pentanoic acid, VPA) is a broad-spectrum antiepileptic drug that is now used commonly for several other neurological and psychiatric indications, it considered to be a safe antiepileptic drug in a wide range of epileptic conditions in children and adults. It is usually well tolerated, but serious complications, including hepatotoxicity, hyperammonemic encephalopathy, fatal hemorrhagic pancreatitis, teratogenicity and bone marrow suppression may occur. VPA is extensively metabolized by the liver via glucuronic acid conjugation, mitochondrial $\beta$ - and cytosolic $\omega$ oxidation to produce multiple metabolites ( GarciaMorales et al., 2007; Lheureux Hantson, 2009 and Wang et al., 2012).

The mechanism of VPA hepatotoxicity is still not understood, although multiple factors are likely to contribute to the toxicity, including development of oxidative stress (Chang and Abbott, 2006), formation of reactive metabolites of VPA (Tang, 2007) and covalent binding to cellular proteins (Leone et al., 2007; Nakayama et al., 2009).

Silymarin is a purified extract from the seeds of Silybum marinum L. (Asteraceae) also called "milk thistle". It was shown that silymarin consists of a large number of flavonoids. Currently, silymarin is widely used as a hepatoprotectant and as a supportive therapy for liver disorders such as cirrhosis, hepatitis and fatty acid infiltration due to alcohol and toxic chemicals (Ball and Kowdley, 2005; Kren and Walterova, 2005).

Silymarin is capable of protecting liver cells directly by stabilizing the membrane permeability through inhibiting lipid peroxidation and preventing liver glutathione depletion (Skottova et al., 2003).

Silymarin has proved success in protecting the liver cell from oxidative effect of carbon tetrachloride, 
paracetamol or D-galactosamine via the antioxidant properties of flavonoids, which includes the inhibition of the synthesis of phosphatidylcholine, stimulating of hepatic synthesis of RNA proteins, stimulate the RNA polymerase I, and further the ribosomal RNA and the protein synthesis ( Ramasamy and Agarwal , 2008). So, this study aims at evaluating the protective effects of silymarin on VPA-induced hepatotoxicity.

\section{Material and methods}

\section{Drugs}

- Valproic Acid sodium (Depakin): 500mg tablets, manufactured by Sanofi Winthrop industry- France.

- Silymarin: Silymarin (Legalon) capsules 140 $\mathrm{mg}$, a product of chemical industries development (CID) Giza Egypt. Under license of MADAUS GmbH Germany.

\section{Experimental Animals}

In this experiment, 70 adult male albino rats weighting 150-200 g were obtained from Animal House in Faculty of Veterinary Medicine, Zagazig University. All animals were subjected to 14 days of passive preliminaries in order to adapt themselves to their new environment and to ascertain their physical wellbeing. They were housed in separate well ventilated cages, under standard conditions, with free access to the standard diet and water ad libitum. The experiment was conducted at the Animal House of Faculty of Medicine , Zagazig University. The experiment was performed in accordance with the "Guide for the Care and Use of Laboratory Animals" (Institute of Laboratory Animal Resources, 1996).

\section{Methods}

\section{Experimental design}

\section{Grouping of animals}

The rats were divided into seven groups; each group consisted of 10 rats.

- Group Ia (Negative control): kept on normal diet and tape water without treatment till end of the experiment.

- Group 1b (Positive control): Sham received $1 \mathrm{ml}$ of $0.9 \%$ saline by gavage for 6 days/week for 8 weeks.

- Group II (silymarin): Rats received $17.5 \mathrm{mg} / \mathrm{kg}$ of silymarin dissolved in $1 \mathrm{ml}$ saline once daily by gavage for 6 days/week for 8 weeks (Kucharz and Kott , 1994).

N.B.: LD50 in rats $385 \mathrm{mg} / \mathrm{kg}$ in rats (Dixit et al., 2007).

- Group IIIa (low dose valproic) : Rats were given $200 \mathrm{mg} / \mathrm{kg}$ VPA dissolved in $0.9 \%$ saline once daily by gavage for 6 days/week for 8 weeks Kabakus et al., (2005), Bairy et al., (2010).

The dose of VPA is based on that administration of an oral dose of
VPA $200 \mathrm{mg} / \mathrm{kg} /$ day or greater represents $50 \%$ of the maximum human daily dose or greater (Walker et al., 1990 and Kabakus et al., 2005).

- Group IIIb (high dose valproic) : Rats were given VPA $400 \mathrm{mg} / \mathrm{kg}$ dissolved in $0.9 \%$ saline once daily by gavage for 6 days/week for 8 weeks (Kabakus et al., (2005) and Bairy et al., (2010)).

- Group IVa (low dose valproic + silymarin): Rats were given 200 $\mathrm{mg} / \mathrm{kg}$ of VPA (dissolved in $0.9 \%$ saline) and silymarin $17.5 \mathrm{mg} / \mathrm{kg}$ (dissolved in $1 \mathrm{ml}$ saline) once daily by gavage for 6 days/week for 8 weeks.

- Group IVb (high dose valproic + silymarin): Rats were given 400 $\mathrm{mg} / \mathrm{kg}$ of VPA (dissolved in $0.9 \%$ saline) and silymarin $17.5 \mathrm{mg} / \mathrm{kg}$ (dissolved in $1 \mathrm{ml}$ saline) once daily by gavage for 6 days/week for 8 weeks.

At the end of the experiment rats were anaesthetized by ether and blood samples were collected from the retro-orbital plexus for estimation of liver functions (ALT and ALP), then rats were sacrificed by decapitation and abdominal incision was done and the liver extracted for measurement of hepatic MDA content and GSH-Px activity as follows:

\section{Assessment of liver function tests (LFTs)}

Alanine aminotransferase (ALT) (IU/L)

Estimation of ALT has been carried out using kits of Eli Tech-diagnostic. It was done as described by Sokmen et al., (2012) quoted from Reitman and Frankel, (1957) according to the pamphlet of Eli techdiagnostic by method of enzymatic UV kinetic.

Alkaline phosphatase enzyme (ALP) (IU/L)

Its estimation has been carried out by twopoint method according to Walter and Schutt, (1974).

\section{Assessment of tissue oxidative stress markers}

Each liver specimen was divided into 2 parts, one part was wrapped with aluminum foil and embedded in liquid nitrogen for 1 hour then kept frozen in $-80^{\circ} \mathrm{C}$ till used to asses MDA level and GSH-px enzyme activity in tissues. Assessment of MDA ( $\mathrm{nmol} / \mathrm{mg}$ protein) level was done as described by Satoh, (1978), while assessment of enzyme activity of GSH-px (nmol/gm tissue) was done according to Durak et al., (1996), this is according to the pamphlet of Bio diagnostic kits using calorimetric method. The 2nd parts were preserved for histopathological examination.

\section{Histologic study}

\section{Light microscope examination (HandE)}

For light microscopic study, liver specimens were fixed in $10 \%$ formalin saline for histopathological examination using Hematoxylin and Eosin (HandE) 
stain by following the method described by Wilson and Gamble, (2002).

\section{Immunohistochemical study}

Immunostaining was performed using the avidin-biotin peroxidase technique for localization of Bcl-2. Paraffin sections mounted on coated slides were deparaffinized and treated with $0.01 \mathrm{M}$ citrate buffer for 10 minutes to unmask antigens. Then sections were incubated in $\mathrm{H} 2 \mathrm{O} 2$ for 10 minutes to abolish endogenous peroxidase activity before blocking with $5 \%$ horse serum for 2 hs at room temperature to inhibit the nonspecific immunoreactions. Primary monoclonal anti- Bcl-2 serum (Cell Marque Lot., 27068) were applied at 1:5000 dilutions. Sections were incubated with primary monoclonal antisera for $36 \mathrm{~h}$ at $4 \mathrm{C}^{\circ}$. After washing they were incubated with biotinylated secondary antibodies for $5 \mathrm{hrs}$ and then followed by avidin-biotin peroxidase complex. Finally immune reaction was visualized with $0.05 \%$ diaminobenzidine. Then the slides were counter stained with Mayer's hematoxylin before mounting (Happerfield et al., 1993).

\section{Statistical analysis}

Data were represented as means \pm SD. The differences were compared for statistical significance by ANOVA and post hoc Tukey's tests. Difference was considered significant at $\mathrm{p}<0.05$. The statistical analysis was performed using Epi-Info version 6.1 (Dean et al., 2000).

\section{Results}

\section{I-Biochemical results}

Statistical comparison between the negative control (Ia), positive control (Ib) and silymarin groups regarding LFTs (ALT and ALP) and hepatic oxidative stress markers (MDA and GSH-Px) revealed no significant difference $(\mathrm{P}>0.05)$ by ANOVA test, so the negative control (Ia) was used for comparison with other groups of the study.

As regard groups IIIa, IIIb, IVa and IVb they showed significant difference $(\mathrm{P}<0.05)$ in LFTs (ALT and ALP) and hepatic oxidative stress markers (MDA and GSH-Px) in comparison with control group (Table 1and Figure 1).

\section{Effects of valproic acid on the hepatic functions (ALTandALP) , MDA contents and antioxidant GSH-PX enzyme activity in liver tissues}

Valproic acid caused significant increase in the mean values of ALT, ALP and hepatic MDA contents $(\mathrm{P}<$ $0.05)$ while GSH-Px activity significantly reduced $(\mathrm{P}<$ 0.05 ) in group IIIa and IIIb when compared with control group. These effects were dose dependent as there was a statistically significant increase in the mean values of ALT, ALP and hepatic MDA contents $(\mathrm{P}<$ $0.05)$ while GSH-Px activity significantly reduced $(\mathrm{P}<$ $0.05)$ in group IIIb $(400 \mathrm{mg} / \mathrm{kg})$ when compared with group IIIa (200 mg/kg) (Table land Figure 1).
Effects of silymarin on the hepatic functions (ALTandALP), MDA contents and antioxidant in liver tissues of rats received valproic acid

Silymarin treatment significantly $(\mathrm{P}<0.05)$ improved the mean values of (ALT andALP) as well as oxidative stress markers (MDA and GSH-Px) in group IVa in comparison with group IIIa but still significantly increased $(\mathrm{P}<0.05)$ in comparison with the control group, which means partial improvement. As regard $\mathrm{IVb}$ group, silymarin treatment significantly improved liver functions (ALT and ALP) and oxidative stress markers (MDA andGSH-Px) in comparison with group IIIb , but still significantly increased when compared with the control, which means partial improvement. As regarding VPA + silymarin treated groups, the improvement was significant $(\mathrm{P}<0.05)$ in group IVa in comparison with IVb for all parameters except ALT (Table 1and Figure 1).

\section{II- Histopathologic results}

Examination of the specimens taken from the control groups (Iaand $\mathrm{Ib}$ ) and silymarin group showed the normal hexagonal lobules with central veins and peripheral hepatic triads (portal areas) contained branches of the portal vein, hepatic artery and bile duct. Hepatocytes are arranged in trabeculae running radiantly from the central vein. They have stippled appearance of the acidophilic cytoplasm with large vesicular nuclei. The trabeculae are separated by sinusoidal spaces (Figure 2). Immunohistochemical stained sections revealed dark brown positive reaction in the cytoplasm of hepatocytes surrounding the central vein (Figure 3).

Examination of HandE stained liver sections of $200 \mathrm{mg} / \mathrm{kg}$ VPA group showed patchy microvesicular steatosis, dilated congested central vein and dilated congested sinusoids in some lobules. There are also cloudy swelling and hydropic degeneration in hepatocytes especially in zone 3 hepatocytes (hepatocytes surrounding central vein) (Figure 4). Immunolocalization of $\mathrm{Bcl}-2$ in all examined liver specimens of this group revealed weak cytoplasmic staining in the hepatocytes surrounding the central vein (Figure 5).

Rats received $200 \mathrm{mg} / \mathrm{kg}$ VPA and silymarin $17.5 \mathrm{mg} / \mathrm{kg}$ showed marked improvement. Hepatic plates return to normal in most areas with decrease in hydropic degeneration. The specimens showed decrease in the congestion and dilation of the central vein and sinusoids. There was marked regression in microvesicular steatosis in most of liver sections (Figure 6). Immunohistochemical stained sections revealed dark brown positive reaction in the cytoplasm of hepatocytes surrounding the central vein (Figure 7).

Examination of HandE stained liver sections of $400 \mathrm{mg} / \mathrm{kg}$ VPA group showed patchy microvesicular steatosis and focal necrosis of hepatocytes (the hepatocytes replaced by neutrophils, especially around central vein), dilated congested central vein and sinusoids in most of the hepatic lobules (Figures 8,9). Immunohistochemical stained sections revealed weak Bcl-2 reaction in the cytoplasm 
of hepatocytes surrounding the central vein (Figure $10)$.

Examination of HandE stained liver sections of rats received $400 \mathrm{mg} / \mathrm{kg} \mathrm{VPA}$ and silymarin $17.5 \mathrm{mg} / \mathrm{kg}$ showed partial improvement. Hepatic plates return to normal in some areas with decrease in hydropic degeneration. The specimens showed decrease in the congestion and dilation of the central vein and sinusoids. There was regression in microvesicular steatosis in some of liver sections (Figure 11). Immunohistochemical stained sections revealed moderate brown positive reaction in the cytoplasm of hepatocytes surrounding the central vein (Figure 12).

Table 1: Statistical comparisons between mean values of serum liver functions (ALT and ALP) and hepatic (MDA, GSH-Px) levels in the different studied groups using ANOVA and post hoc Tukey's tests.

\begin{tabular}{|l|c|c|c|c|c|c|c|}
\hline \multicolumn{1}{|c|}{$\begin{array}{c}\text { Groups } \\
\text { N= 10 }\end{array}$} & $\begin{array}{c}\text { Negative } \\
\text { control } \\
\text { (Ia) }\end{array}$ & $\begin{array}{c}\text { Low dose } \\
\text { VPA (IIIa) }\end{array}$ & $\begin{array}{c}\text { High dose } \\
\text { VPA (IIIb) }\end{array}$ & $\begin{array}{c}\text { Low dose } \\
\text { VPA + S (IVa) }\end{array}$ & $\begin{array}{c}\text { High dose VPA } \\
+ \text { S (IVb) }\end{array}$ & F test & P value \\
\hline ALT(IU/L) & $302.6 \pm 2.8^{\S}$ & $411 \pm 31.7$ & $554 \pm 34.7^{\mathrm{a}}$ & $364 \pm 32.3^{\mathrm{b}}$ & $365.1 \pm 36.9^{\mathrm{b}}$ & 96.92 & $*<0.001$ \\
\hline $\begin{array}{l}\text { Alkaline Phosphatase } \\
\text { (IU/L) }\end{array}$ & $14.4 \pm 1.4^{\S}$ & $21 \pm 1.4$ & $32.8 \pm 1.8^{\mathrm{a}}$ & $17 \pm 1.6^{\mathrm{b}, \mathrm{c}}$ & $24.6 \pm 1.2^{\mathrm{b}}$ & 222.49 & $*<0.001$ \\
\hline $\begin{array}{l}\text { MDA (nmol/mg } \\
\text { protein) }\end{array}$ & $3.3 \pm 0.4^{\S}$ & $5.8 \pm 0.6$ & $8.1 \pm 0.7^{\mathrm{a}}$ & $4.1 \pm 0.5^{\mathrm{b}, \mathrm{c}}$ & $5.1 \pm 0.6^{\mathrm{b}}$ & 104.69 & $*<0.001$ \\
\hline $\begin{array}{l}\text { Glutathione } \\
\begin{array}{l}\text { Peroxidase (nmol/gm } \\
\text { tissue) }\end{array}\end{array}$ & $164.4 \pm 2.8^{\S}$ & $143 \pm 2.5$ & $122 \pm 1.3^{\mathrm{a}}$ & $153 \pm 2.7^{\mathrm{b}, \mathrm{c}}$ & $134.7 \pm 4.3^{\mathrm{b}}$ & 320.91 & $*<0.001$ \\
\hline
\end{tabular}

*Significant difference; $S=$ silymarin; $N=$ Number

$\left.{ }^{\S}\right)$ Significant difference $(p<0.05)$ when compared with IIIa, IIIb, IVa and IVb using post hoc Tukey's test.

(a) Significant difference $(P<0.05)$ compared with IIIa using post hoc Tukey's test.

(b) Significant difference $(p<0.05)$ when compared with IIIa and IIIb respectively using post hoc Tukey's test.

(c) Significant difference $(p<0.05)$ when IVa compared with IVb using post hoc Tukey's test.

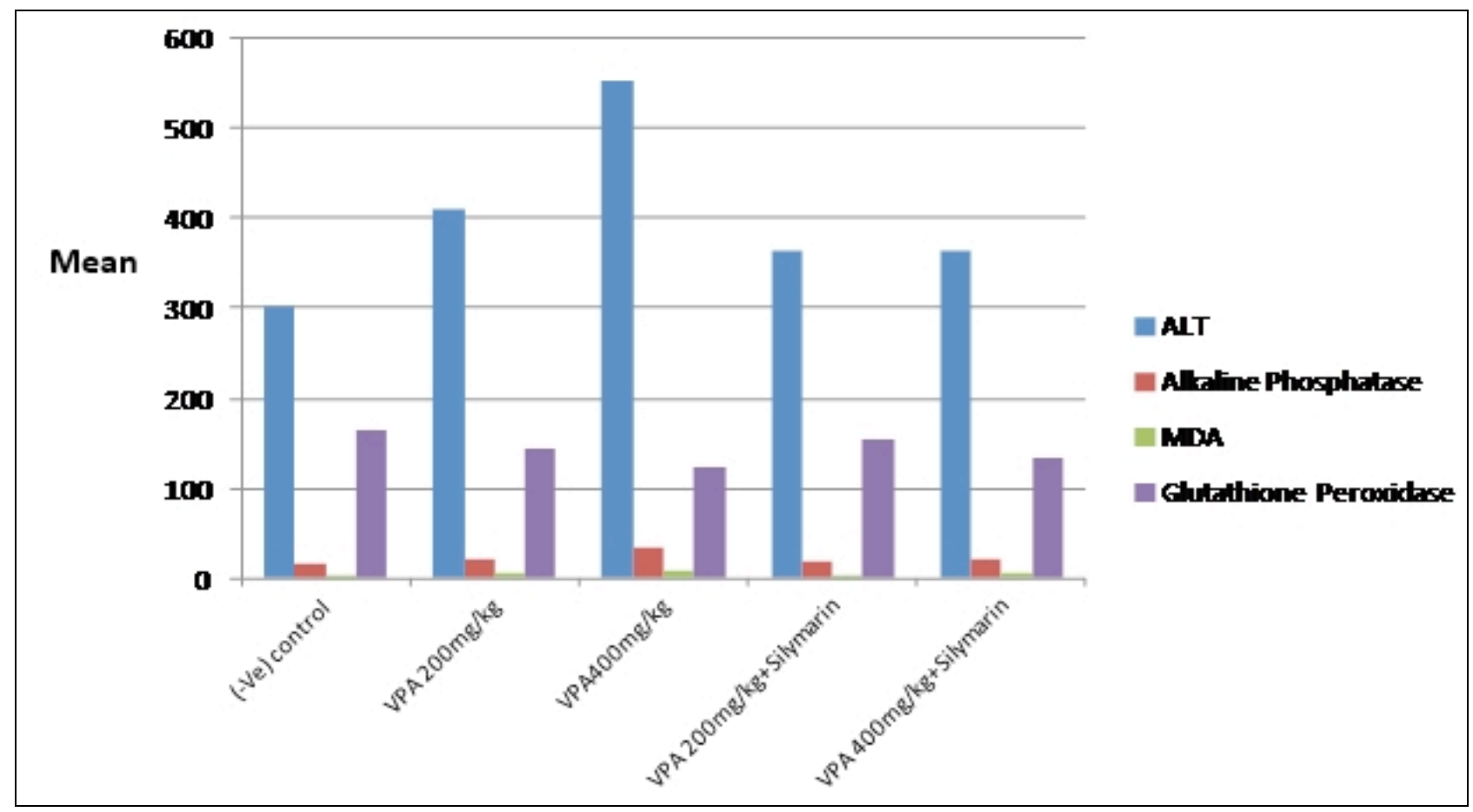

Figure (1): Mean serum Alanine Transaminase, Alkaline Phosphatase, MDA and Glutathione Peroxidase) in the different studied groups. 


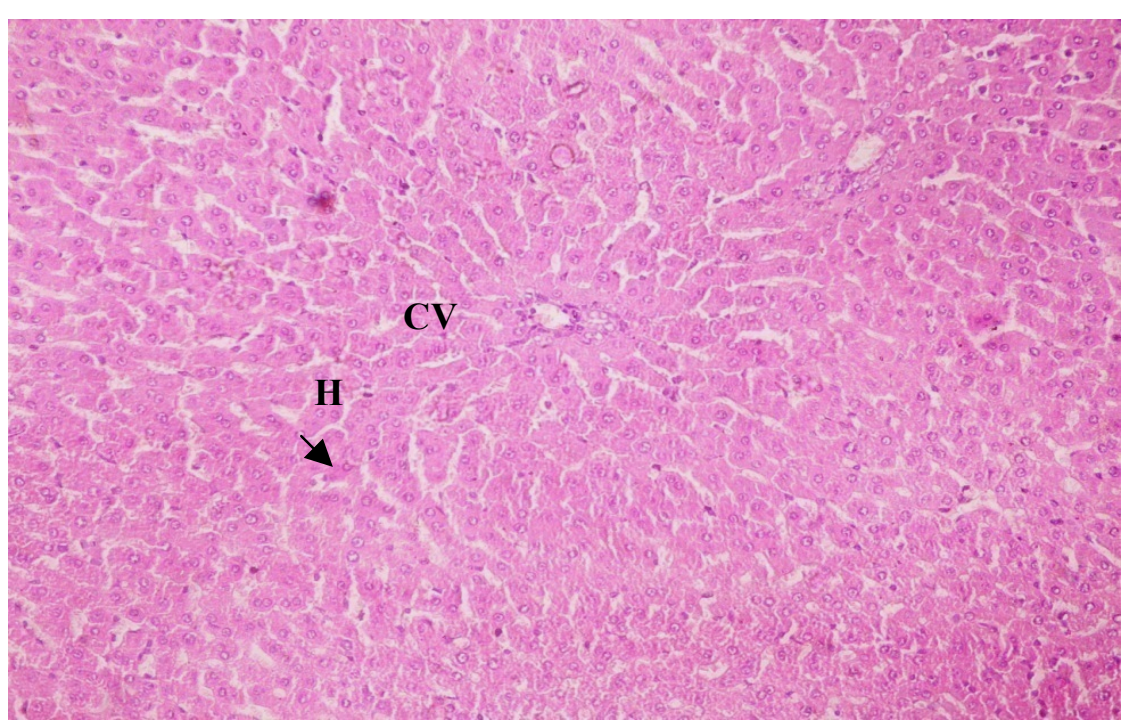

Figure (2): A photomicrograph of a rat liver (negative control group) showing part of hepatic lobule with central vein $(\mathrm{CV})$ and sheets of hepatocytes $(\mathrm{H})$ with sinusoidal spaces in between (arrows). (HandE X200)

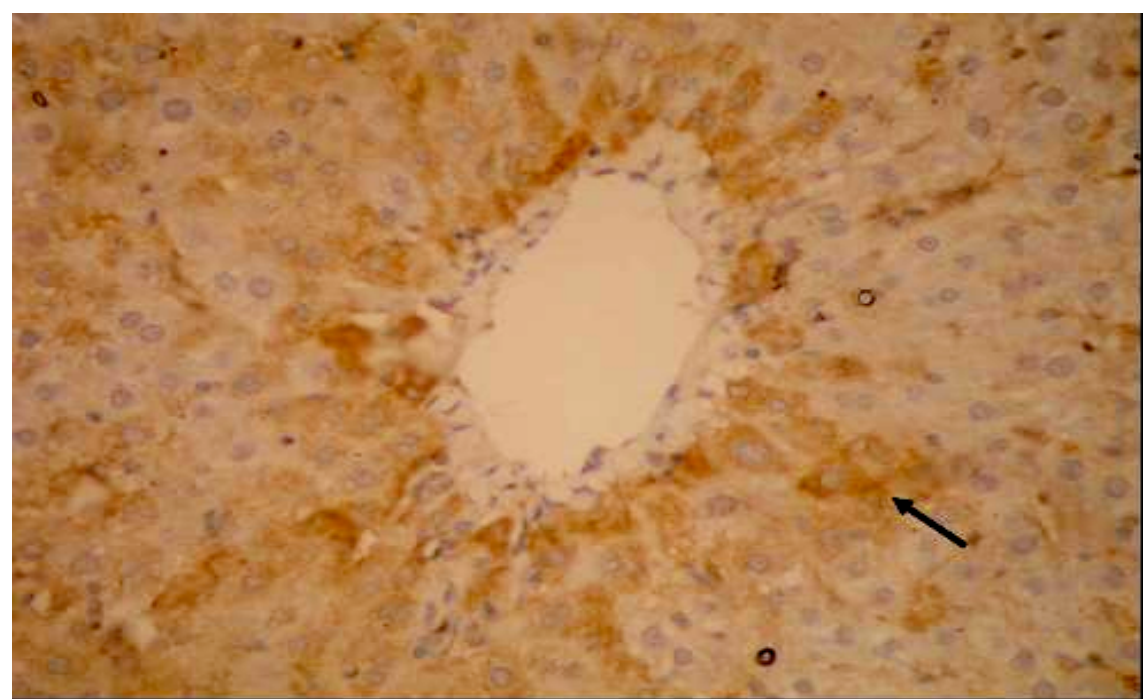

Figure (3): A photomicrograph of a rat liver (negative control group) showing positive cytoplasmic staining by Bcl-2 of hepatocytes surrounding central vein (arrow). (ABC, DAB , M . H counter stain X200)

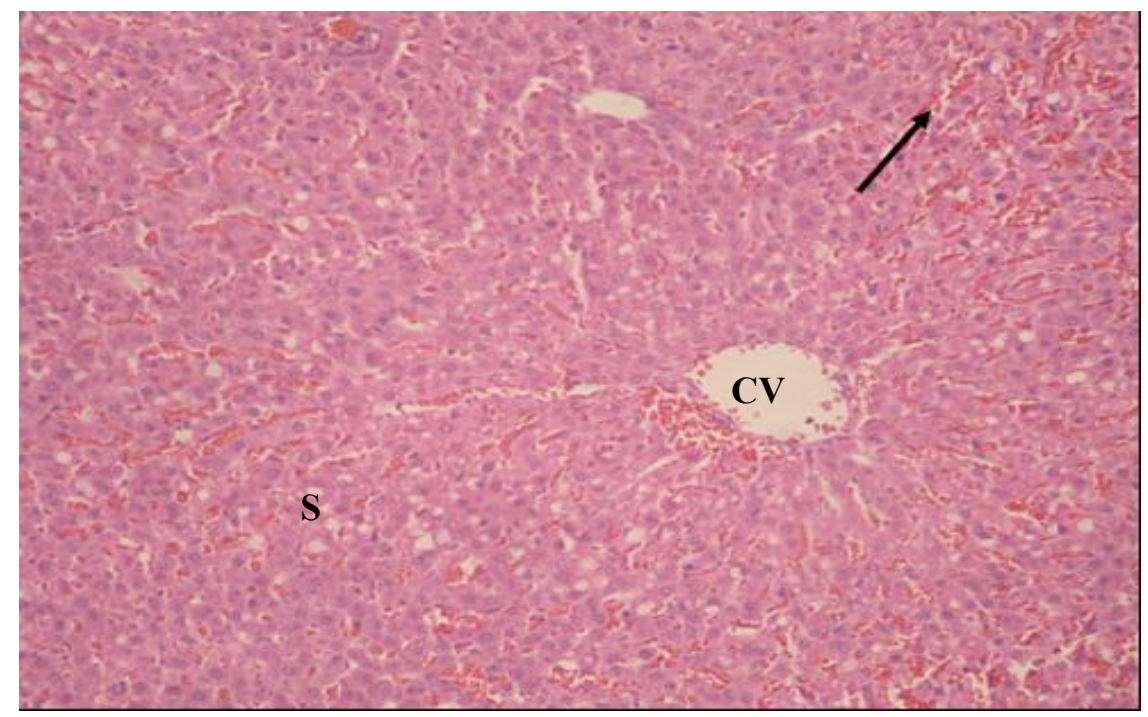

Figure (4): A photomicrograph of a rat liver section of group IIIa (200 mg/ kg VPA for 8 weeks) showing dilation of central vein and marked congestion of sinusoids (arrow) with mild microvesicualr steatosis (S). (Hx and E, X100) 


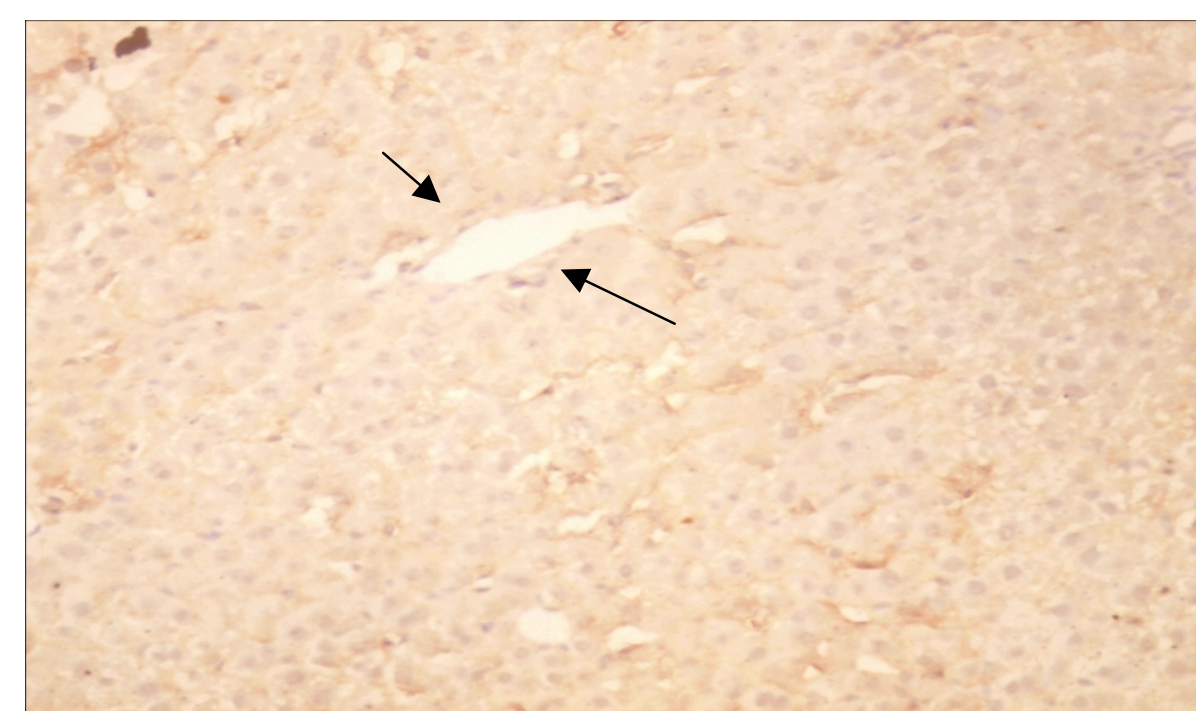

Figure (5): A photomicrograph of a rat liver section group IIIa (200 mg/ kg VPA for 8 weeks) showing weak cytoplasmic staining of hepatocytes by BCL2 around central vein (arrow). (ABC, DAB , M . H counter stain X200)

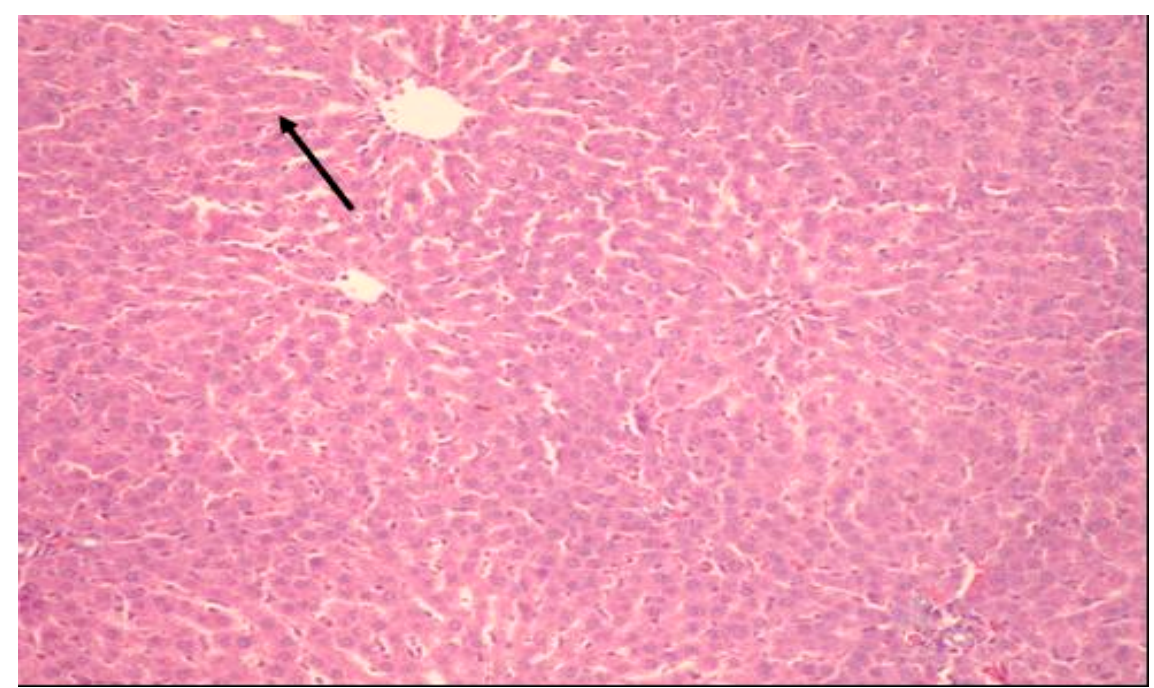

Figure (6): A photomicrograph of a rat liver section of group IVa (200 mg/ kg VPA + silymarin $17.5 \mathrm{mg} / \mathrm{kg}$ for 8 weeks) showing decrease in the congestion of sinusoids and central vein. Hepatocytes return to normal (arrow). There is marked regression in steatosis. ( $\mathrm{Hx}$ and $\mathrm{E}, \mathrm{X100})$ 


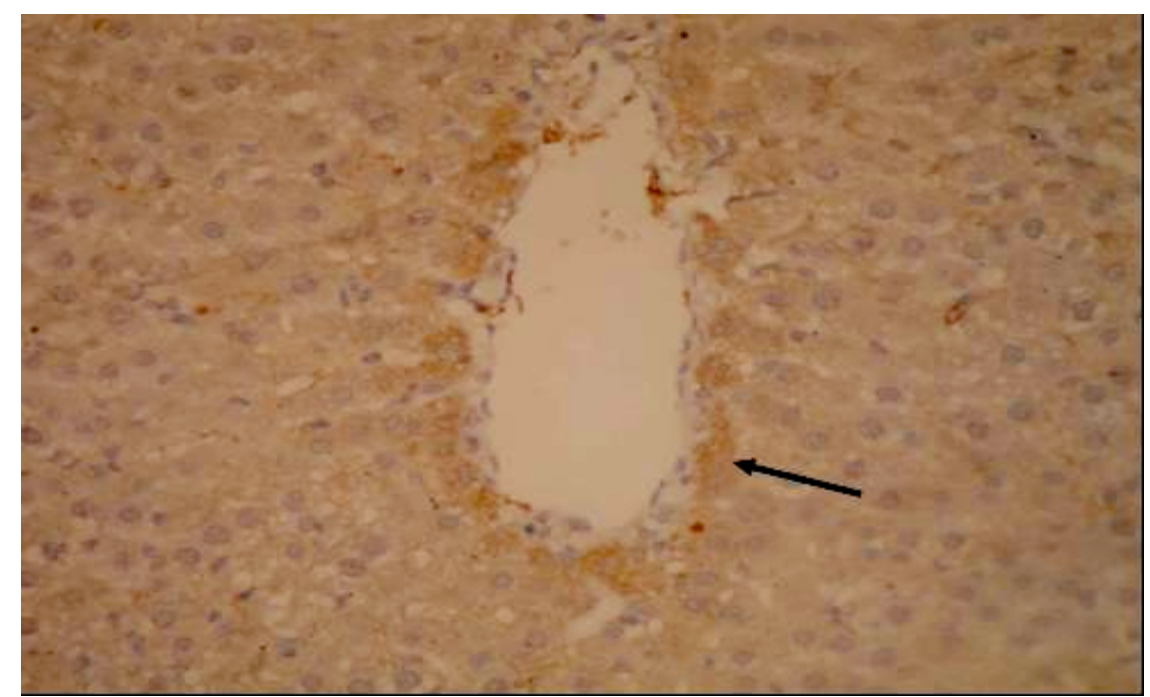

Figure (7): A photomicrograph of a rat liver section of group VIa (200 mg/ kg VPA + silymarin $17.5 \mathrm{mg} / \mathrm{kg}$ for 8 weeks) showing positive cytoplasmic staining by Bcl-2 of hepatocytes surrounding central vein (arrow). (ABC, DAB , M . H counter stain X200)

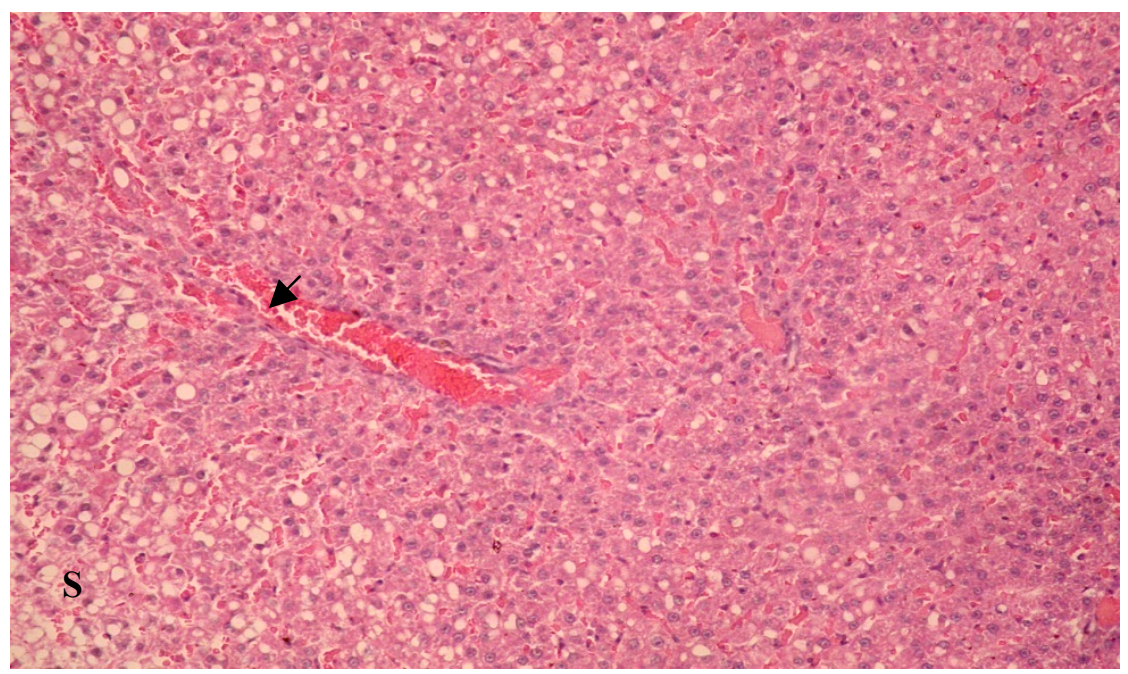

Figure (8): A photomicrograph of a rat liver section of group IIIb (400 $\mathrm{mg} / \mathrm{kg} \mathrm{VPA}$ for 8 weeks) showing congestion and dilation of sinusoids (arrow), enlarged hepatocytes with cloudy swelling and patchy microvesicular steatosis (S). (Hx and E, X100) 


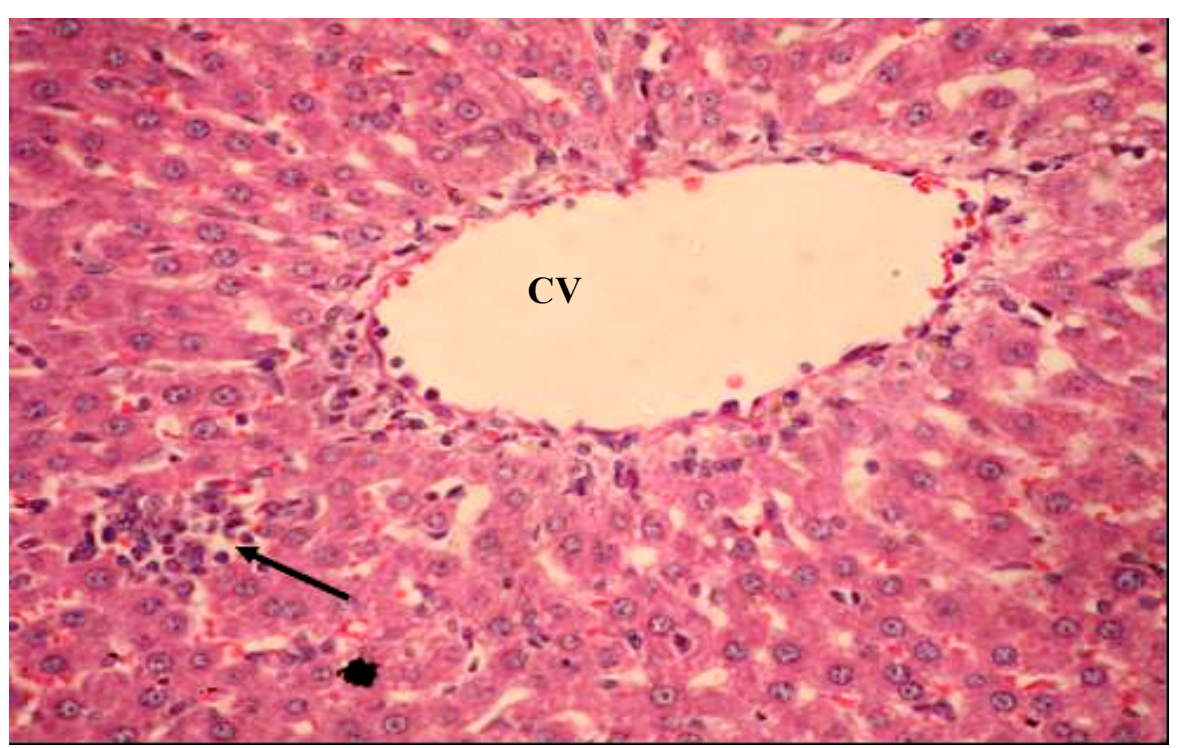

Figure (9): A photomicrograph of a rat liver section of group IIIb (400 $\mathrm{mg} / \mathrm{kg}$ VPA for 8 weeks) showing marked dilation of the central vein $(\mathrm{CV})$, hepatocytes surrounding central vein are enlarged and show cloudy swelling and focal necrosis (replaced by inflammatory cells) (arrow). (Hx and E, X200)

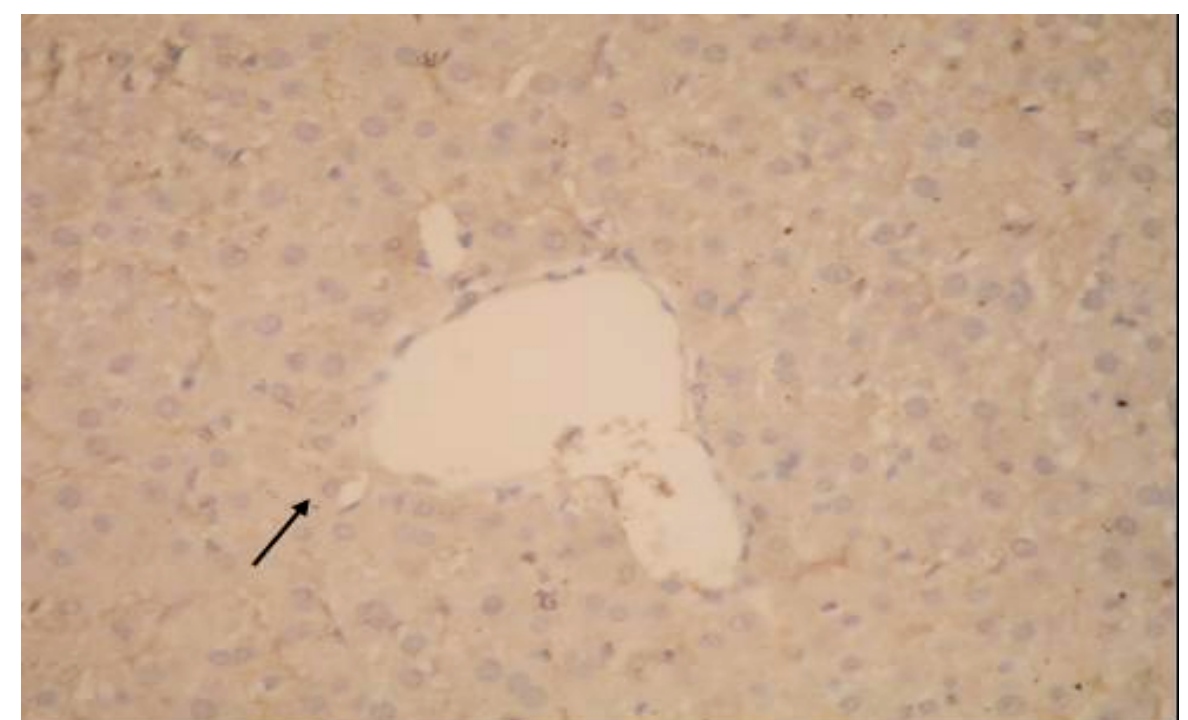

Figure (10): A photomicrograph of a rat liver section of group IIIb (400 mg/ kg VPA for 8 weeks) showing weak cytoplasmic staining of hepatocytes by BCL-2 around central vein (arrow). (ABC, DAB , M . H counter stain X200) 


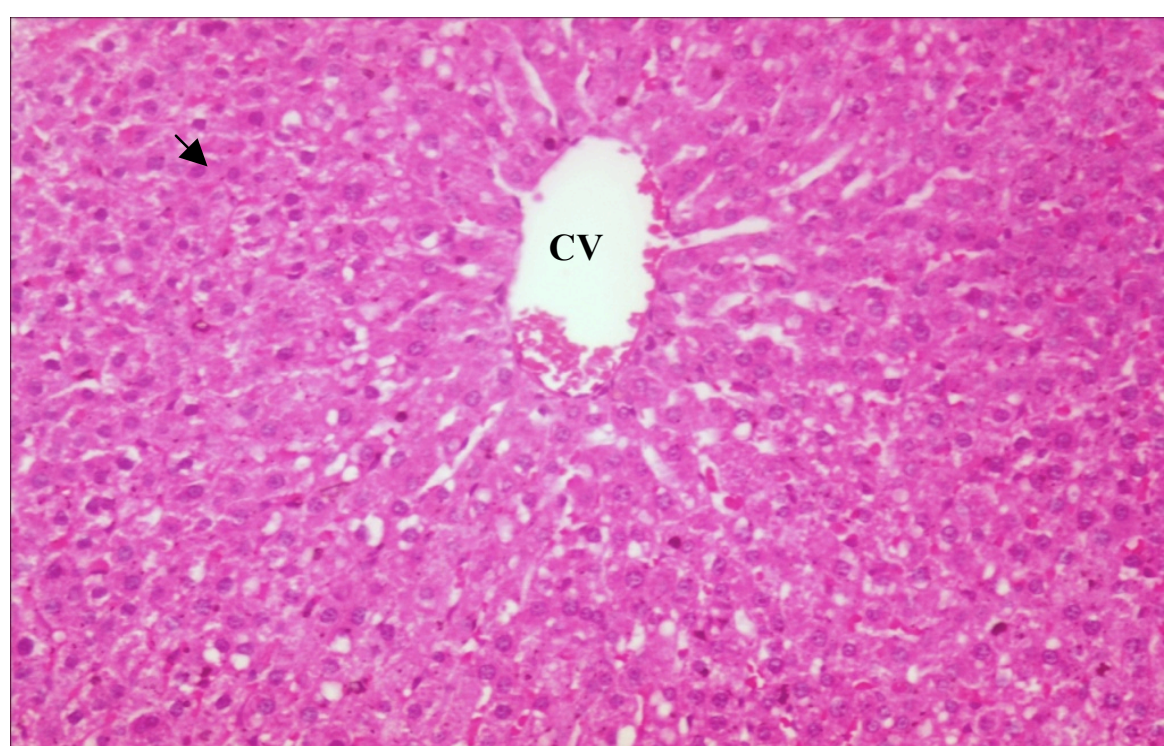

Figure (11): A photomicrograph of a rat liver section of group IVb (400 mg/ kg VPA + silymarin $17.5 \mathrm{mg} / \mathrm{kg}$ for 8 weeks) showing decrease in the congestion of sinusoids and central vein (CV). Hepatocytes return to normal in some areas (arrow). There is partial regression in steatosis. (Hx and $\mathrm{E}, \mathrm{X100})$

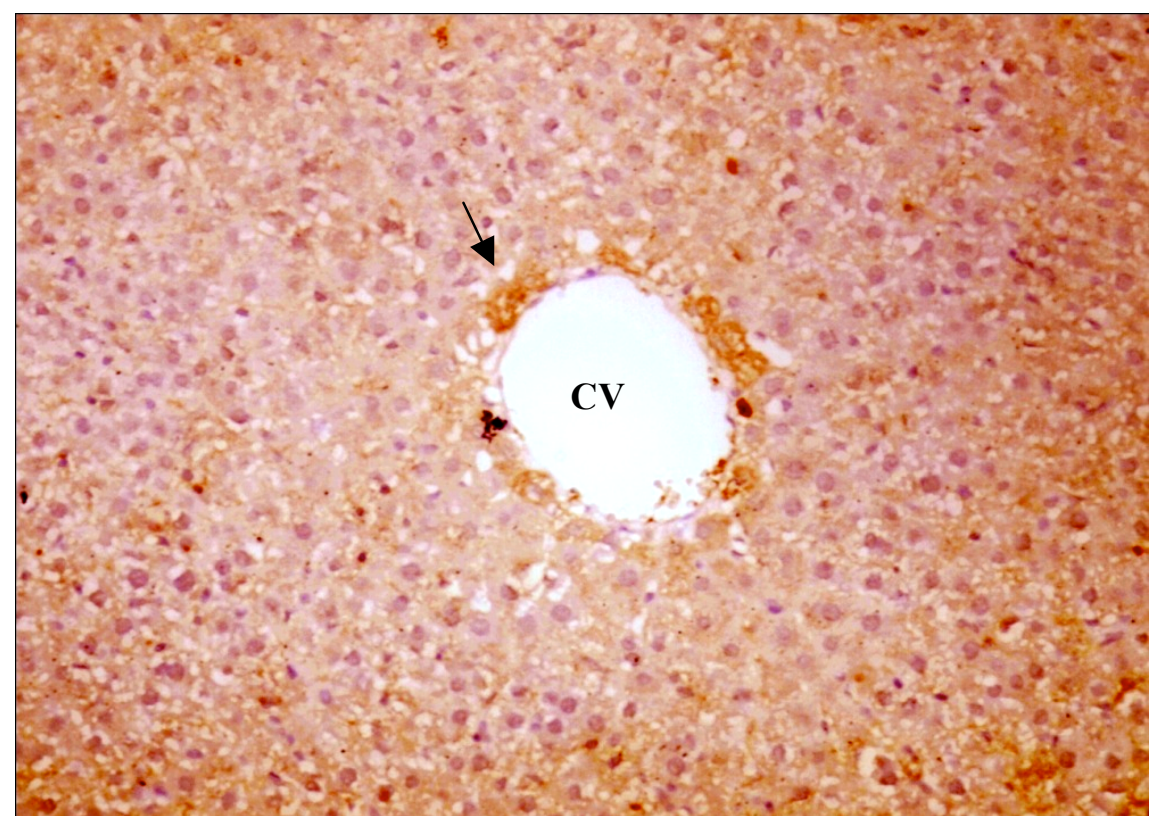

Figure (12): A photomicrograph of a rat liver section of group IVb (400 mg/ kg VPA + silymarin $17.5 \mathrm{mg} / \mathrm{kg}$ for 8 weeks) showing moderate cytoplasmic staining of hepatocytes by Bcl-2 around central vein (CV) (arrow). (ABC , DAB, M . H counter stain X200)

\section{Discussion}

This study evaluated the potential protective effects of silymarin against VPA-induced liver damage in experimental animals. The results indicated that VPA induced dose dependent hepatotoxicity and associated with increased ALT and ALP. In accordance with these results, Schulpis et al., (2006) and Sokmen et al., (2012) found that VPA treated rats showed significant increase in the levels of hepatocellular (AST, ALT) and hepatobiliary (ALP) enzymes compared to control rats.

Explanation of the increment of serum AST and ALT which are employed in the diagnosis of hepatic damage might be due to cytoplasmic location of these enzymes which are released into the circulation after cellular damage (Singh et al., 2001).
The increase in ALP level could be interpreted by Higgins, et al., (2001) and Tong et al., (2005) who stated that VPA is metabolized by fatty acid $\beta$ oxidation and conjugated by glucuronic acid with a minimal contribution by omega oxidation, chronic or high-dose VPA therapy inhibits $\beta$-oxidation. This causes a decrease in benign metabolites of $\beta$-oxidation and increases toxic metabolites of omega oxidation in compensation, which cause injury to bile duct epithelium.

Concerning the oxidative stress effects on hepatic tissues which appeared in the form of significant increase in MDA level, more evident in high dose VPA group, this was coincided with Siddiqui et al., (1999) and Tong et al., (2005). These findings 
could be explained by Tabatabaei and Abbott, (1999), who stated that VPA induced cytotoxicity through generalized formation of oxygen radicals against nuclear DNA. Also, Na et al., (2003) mentioned that cytotoxic activity of VPA is the result of generation of hydrogen peroxides and production of highly reactive hydroxyl radicals. Furthermore, it enhances the clearance of selenium, copper and zinc, subsequently leading to decreased synthesis of free radicals scavenging enzymes such as glutathione peroxidase and glutathione reductase activities. In addition, Pourahmad et al., (2012) reported that, cytotoxic action of VPA is mediated by lysosomal membrane leakiness along with reactive oxygen species (ROS) formation . Also, incubation of hepatocytes with VPA also caused rapid hepatocyte glutathione (GSH) depletion which is another marker of cellular oxidative stress.

Results of light microscope examination of stained liver sections of the present study had supported the above mentioned biochemical results where rats received VPA $(200 \mathrm{mg} / \mathrm{kg})$ showed patchy microvesicular steatosis, dilated congested central vein and sinusoids in some lobules. With increasing the dose of VPA (400 mg/kg), patchy microvesicular steatosis and focal necrosis of hepatocytes, in most of hepatic lobules were observed. VAP administration resulted in cells with weak cytoplasmic staining/localization of $\mathrm{Bcl} 2$ in the hepatocytes surrounding the central vein. It was weaker localized in group IIIb than IIIa.

Silymarin administration showed partial improvement. Hepatic plates return to normal in some areas as regarding marked regression in microvesicular steatosis in most of liver sections especially that received low dose VPA and partially regressed in high dose VPA. Bcl-2 localization revealed dark brown positive reaction in low dose VPA group and moderate brown positive reaction in high dose VPA group.

The histopathological findings of this study coincided with Baran et al., (2004) who mentioned that hepatic sections of rats treated with VPA showed congestion and dilatation of central veins, perivenullar sinusoids, increased vascularization, dilatation and microvesicular steatosis. In addition, degeneration and inflammation at the periportal zone were also detected.

These results were in accordance with Tong et al., (2005); Khan et al., (2005); and Lee, (2007), who detected steatosis of zonal distribution conforming to the centrilobular zones, extensive necrosis, inflammatory cell infiltrations and dose / timedependent fatty changes around the central vein in liver sections of rats received VPA. In addition, Ibrahim, (2012) reported that VPA treated mice showed histopathological changes which included partial to severe distortion of liver architecture, congested vasculature, scattered to multifocal necrotic areas with focal aggregates of inflammatory cells, vacuolar degenerative changes, enlarged atypical hepatocytes, variation in nucleus regarding to size and shape and hypertrophied nucleus with fragmented chromatin.

The improvement that occurred after coadministration of silymarin with VPA could be explained by Vaziri and Rodriguez-Lturbe, (2006);
Zarban and Ziaee, (2008) who stated that silymarin is a free radical scavenger and a membrane stabilizer which prevents lipid peroxidation and its associated cell damage in some experimental models. Silymarin can be very effective antioxidant and can protect biological systems against the oxidative stress.

\section{Conclusion}

The results of this study have shown that silymarin has protective effects against VPA induced hepatotoxicity, which might be due to the scavenging of free radicals. Therefore, we suggest that silymarin is potentially useful for the prevention of liver toxicity secondary to chronic administration of VPA.

\section{Recommendation}

- Silymarin recommended for patients on chronic or high-dose VPA therapy.

- More studies with higher doses of silymarin are needed to evaluate its protective role on high doses of VPA therapy.

\section{References}

Bairy L, Paul V and Rao Y (2010):Reproductive toxicity of sodium valproate in male rats Indian J. of Pharmacology, Vol. 42, No. 2, March-April, pp. 90-94

Ball KR and Kowdley KV (2005): A review of Silybum marianum (milk thistle) as a treatment for alcoholic liver disease. J. Clin.Gastroenterol., 39(6): 520-528.

Baran OP, Yıldırım A and Akkuş M (2004) :The Protective Role of Folic Acid and Vitamin E Against Toxical Effects of Valproic Acid on Liver Tissue During Period of Gestation. Dicle Tıp Dergisi Cilt:31, Sayı:4, (17-23).

Chang TKH and Abbott FS (2006): Oxidative stress as a mechanismof valproic acid-associated hepatotoxicity. Drug Metab. Rev. 38, 627639.

Dean AG, Dean JA and Coulombier D et al., (2000): Epi-Info (6.1): A word processing data base and statistical program for epidemiology and microcomputer office, Center for disease control, Atlanta Georgia, USA.

Dixit N Baboota S and Kohli K (2007): Silymarin:Areview of pharmacological aspects and bioavailability approaches. Indian J Pharmacol. Vol 39. 4 , 172-179. Quoted from, Leecmte J. Pharmacologic of silybin and silymarin. Rev. Med. Liege(1975); 30:110-4.

Durak I, Canbolat O, kavutch M et al ., (1996): Activities of total, cytoplasmic and mitochondrial superoxide dismutase enzyms in sera and pleural fluids from patients with lung cancer. J. Clin. Lab. Anal., 10:17-20.

Garcia-Morales I, Sancho and Rieger J et al., (2007): Antiepileptic drugs: from scientific evidence to clinical practice. Neurologist 13, S20-S28. 
Happerfield LC, Bobrow LG, Bains RM et al.. (1993): Peroxidase labeling immunocytochemistry: a comparison of elevencommercially available avidin-biotin systems. J Histochem. Cytochem., 41: 291-302.

Higgins S Carroll YL and McCarthy SN (2001): Susceptibility of LDL to oxidative modification in healthy volunteers supplemented with low doses of n3 polyunsaturated fatty acids, Br. J. Nutr. 85 , 23-31.

Ibrahim M (2012): Evaluation of Hepatotoxicity of Valproic acid in albino mice, Histological and Histoistochemical Studies Life Science Journal; 9(4)

Kabakus N, Ay I, Aysun S and Söylemezoglu F(2005):Protective Effects of Valproic Acid Against Hypoxic-Ischemic Brain Injury in Neonatal Rats J. Child Neurol. 20: 582.

Kaplowitz N (2001): Causality assesment versus guilt by association in drug hepatoxicity. Hepatology 33, 308-310.

Khan SK, Abdul shakoor K and Jan MA (2005): Study of histopathologic changes in the liver of albino rats, induced by toxic doses of valproic acid GOMAL J. of Medical Sciences. vol. 3, no. 1

Kren V and Walterova D (2005) :Silybin and silymarin -new effects and applications. Biomed. Pap. Med. Fac.Univ Palacky. Olomouc. Czech. Repub., 149(1): 29-41.

Kucharz EJ and Kott T (1994) : Hepatoprotective activity of silymarin in rats treated with high doses of acetyl salicylic acid or naproxen , Medical $J$ of the Islamic Republic of Iran, Volume: 8 Number 3.

Lee M, Hong I and Kim M (2007): Gene expression profiles of murine fatty liver induced by the administration of valproic acidToxicology and Applied Pharmacology 220 45-59

Leone AM, Kao LM and McMillian MK. Et al., (2007): Evaluation of felbamate and other antiepileptic drug toxicity potential based on hepatic protein covalent binding and gene expression. Chem. Res. Toxicol. 20, 600-608.

Lheureux PR and Hantson P ( 2009): Carnitine in the treatment of valproic acid-induced toxicity Vol. 47, No. 2 , Pages 101-111

$\mathrm{Na}$ L, Wartenberg $\mathrm{M}$ and $\mathrm{Nau} \mathrm{H}$ et al., (2003): Anticonvulsant valproic acid inhibits cardiomyocyte differentiation of embryonic stem cells by increasing intracellular levels of reactive oxygen species. Birth Defects Res A clin. Mol. Teratol.; 67(3):174-80.

Nakayama S, Atsumi Rand Takakusa H et al.. (2009): Azone classification system for risk assessment of idiosyncratic drug toxicity using daily dose and covalent binding. Drug Metab. Dispos. 37, 1970-1977.

Perucca E (2002): Pharmacological and therapeutic properties of valproate: a summary after 35 years of clinical experience. CNS Drugs; 16 : 695-714.
Pourahmad J, Eskandari MR and Kaghazi Aet al., (2012 ): A new approach on valproic acid induced hepatotoxicity: involvement of lysosomal membrane leakiness and cellular proteolysis. Toxicol. In Vitro.; 26(4):545-51.

Ramasamy, K. and Agarwal, R. (2008): Cancer Letters, 269, 352-362.

Reitman S and Frankle S 1957): Glutamic oxaloacetic transaminse colorimetric method. Am. J. Clin. Pathol., 28: 56.

Satoh K ( 1978): Serum lipid peroxide in cerebrospinal disorders determined by new colorimetric methods. Clin. Chim. Acta., 90:37- 43.

Schulpis K, Lazaropoulou C and Regoutas R (2006): Valproic acid monotherapy induces DNA oxidative damage. Toxicology 217, 228-232 .

Siddiqui MA, Nazmi AS and Razia K et al., (1999): Oxidative damage in mice liver induced by sodium valproate: Protection by melatonin. Ind. J. Pharmacol.;31:427-30

Singh SN, Vats, P, Suri S, et al.. (2001): Effect of an antidiabetic extract of Catharanthus roseus on enzymic activities in streptozotocin induced diabetic rats. J. Ethnopharmacol. 76, 269277.

Skottova N, Vecera R andUrbanek K et al., (2003): Effects of polyphenolic fraction of silymarin on lipoprotein profile in rats fed cholesterol rich diets. Pharmacol. Res., 47(1): 17-26.

Sokmen B, Tunali S and Yanardag R (2012): Effects of vitamin $U$ (S-methyl methionine sulphonium chloride) on valproic acid induced liver injury in rats. Food and Chemical Toxicology $50: 3562-3566$.

Tabatabaei AR and Abbott FR (1999): Assessing the mechanism of metabolism dependent valproic acid induced in vitro cytotoxicity.Chem. Res. Toxicol. 12, 323-330.

Tang W (2007): Drug metabolite profiling and elucidation of drug-induced hepatotoxicity. Expert Opin. Drug Metab. Toxicol. 3, 407420.

Tong V, Teng X andChang T et al ., (2005) : Valproic Acid I: Time Course of Lipid Peroxidation Biomarkers, Liver Toxicity, and Valproic Acid Metabolite Levels in Rats Toxicological sciences 86(2), 427-435.

Vaziri ND and Rodríguez-Iturbe B (2006): Mechanisms of disease: Oxidative stress and inflammation in the pathogenesis of hypertension. Nat. Clin. Pract. Nephrol.; 2(10):582-593.

Walker RM, Smith GS and Barsoum NJ et al., ( 1990): Preclinical toxicology of the anticonvulsant calcium valproate. Toxicology; 63:137-55

Walter K and Schutt C( 1974): Acid and alkaline phosphatase in serum (two-point method). In: Bergmeyer, H.U. (Ed.), Method of Enzymatic Analysis, vol. 2. Springer, Newyork, pp. 856860.

Wang W, Lin R and Zhang J (2012): Involvement of fatty acid metabolism in the hepatotoxicity 
induced by divalproex sodium. Hum. Exp. Toxicol. 31(11):1092-101.

Wilson I and Gamble M (2002):The hematoxylins and eosins, In: Theory and practice of histological techniques, Bancroft JD and Gamble M (eds.), 5th ed., Churchill Livingston, Elservier Science Limited, London, UK, pp. 125- 138.

Zarban A and Ziaee M (2008): Evaluation of antioxidant properties of silymarin and its potential to inhibit peroxyl radicals in vitro. Pak. J. Pharm. Sci.; 21(3):249-254.

\section{الملخص العزبي \\ تأثير السيليمارين على التسمم الكبدي الناتج عنب جامض الفالبرويك في ذكور الجرذان البيضاء}

\section{شيرين احمد الخطيب و منار حامد عرفه1 و تيسير رفعت إبراهيم2}

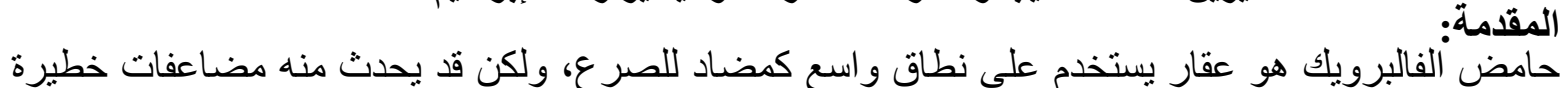

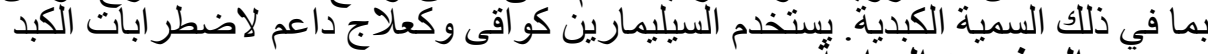

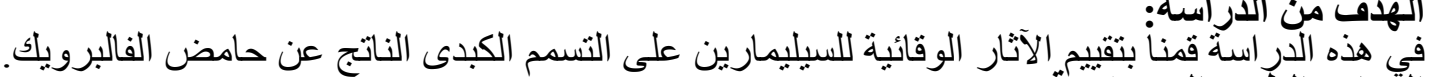

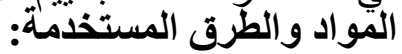

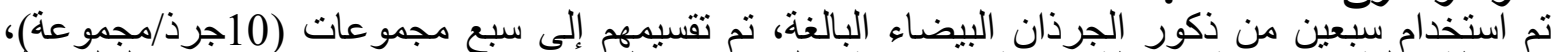

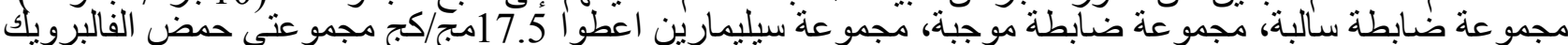

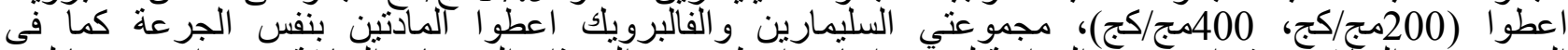

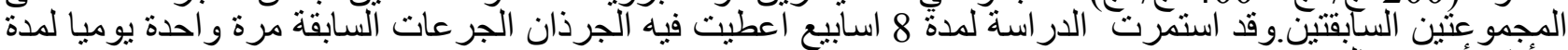

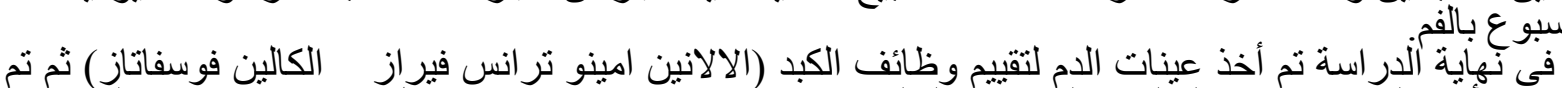

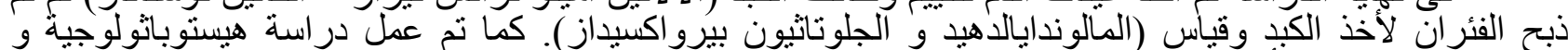
هيستو كيمائية مناعية لأنسجة الكبد. النتائج:

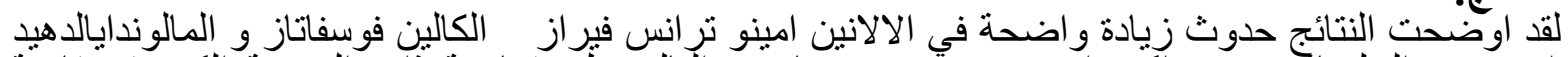

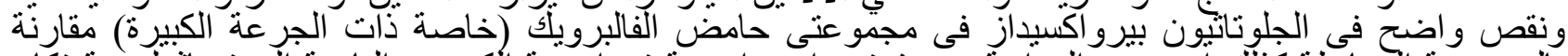

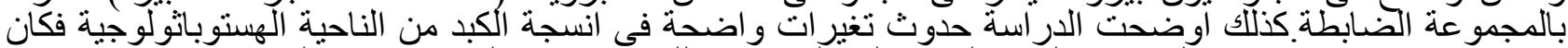

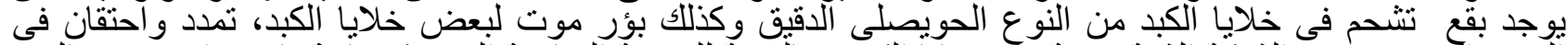

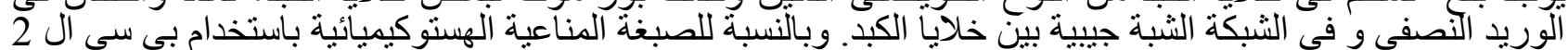

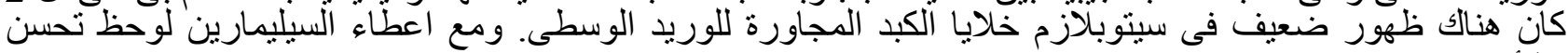

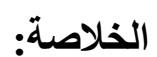

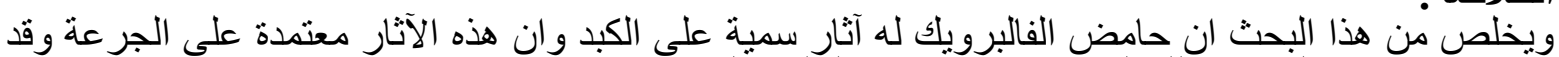
جزئي. تقل هذه الاثثار بالاستخدام المنز امن للسيليمارين مع حامض الفيك لفالبروئكية. 